\title{
As novas formas do falso: entretenimento, desinformação e política nas redes digitais
}

\section{Marcio Serelle}

Pontifícia Universidade Católica de Minas Gerais, Programa de Pós-Graduação em Comunicação Social, Belo Horizonte, MG, Brasil

ORCID: https://orcid.org/0000-0001-6124-5464

\section{Rosana de Lima Soares}

Universidade de São Paulo, Escola de Comunicações e Artes, São Paulo, SP, Brasil ORCID: https://orcid.org/0000-0003-4250-9537

\section{Resumo}

A partir das formas culturais (memes, gifs, áudios, vídeos, entre outros) que circularam nas redes digitais durante as eleições brasileiras de 2018, este ensaio investiga a articulação entre entretenimento e informação no embate político, em que se disseminaram informações falsas por meio de discursos que oscilaram da ludicidade à violência. A hipótese é a de que essas formas, emergentes de um substrato cultural constituído historicamente por hibridações, acabaram por se justapor ou mesmo sobrepor àquelas do jornalismo de referência no cotidiano dos eleitores. A comunicação dessas formas, por meio de estruturas profissionais, opera com narrativas de intensidade emotiva para grupos segmentados. Como na lógica do entretenimento, instaurou-se, nesse debate político, um mundo à parte, em que a vinculação com a realidade imediata se tornou irrelevante.

\section{Palavras-chave}

Comunicação. Política. Entretenimento. Informação falsa. Jornalismo. 


\section{Introdução}

Quando o buchicho ganha mais vida que qualquer conhecimento, ele vira verdade de quebrada em quebrada, e uma certeza não vale mil verdades. (Ferréz).

Os gritos das pessoas que ocuparam o gramado da Esplanada dos Ministérios, em Brasília, foram a parte mais reveladora da posse de Bolsonaro, em 1ํㅡ. de janeiro. Eufórica, a massa berrava: 'WhatsApp! WhatsApp! Facebook! Facebook! (Eliane Brum).

O fenômeno comunicativo das eleições de 2018, em que os embates principais se deram à margem dos meios tradicionais e hegemônicos, colocou a crítica midiática diante de uma nova variedade de textos, pelo modo como eles se propagam, articulam informação e

entretenimento e soldam comunidades. A expectativa de que as redes digitais desempenhariam função primordial no pleito estabelecera-se pelo menos desde as eleições de 2014, com a polarização em nossas mídias sociais, e depois, em 2016, com o resultado do referendo acerca do Brexit e a eleição de Donald Trump nos Estados Unidos, ambos favoráveis a grupos situados à direita do espectro político. Essas duas últimas campanhas foram marcadas, ainda, pela denúncia de uso de dados privados do Facebook ${ }^{1}$. Além desses, os plebiscitos sobre o acordo de paz na Colômbia (outubro de 2016), em que o "não" surpreendentemente ganhou com uma diferença de apenas $0,4 \%$, ou sobre a independência da Catalunha, na Espanha (outubro de 2017), que gerou uma crise interna com vitória de 90\% a favor da separação, são acontecimentos integrantes da mesma lógica do uso de redes digitais para interferência em resultados políticos.

Tais eventos levaram David Alandete, diretor adjunto do jornal espanhol El País, a afirmar que "as democracias, também na América Latina, devem tomar medidas de proteção contra uma máquina industrial que alimenta falsas notícias ao longo dos processos democráticos, com efeitos desastrosos" (EL PAÍS, 2018a). Nos países do continente com democracias mais recentes e marcadas por autoritarismo militar, além de conservadorismo moral e religioso, as consequências desse uso podem ser graves. Ainda assim, resultados do primeiro turno das eleições brasileiras de 2018 foram recebidos com surpresa, uma vez que os institutos de pesquisa não captaram o movimento do eleitorado. A explicação de

\footnotetext{
1 Nos dois pleitos, houve atuação da empresa Cambridge Analytica, do Reino Unido, acusada de roubar dados de 50 milhões de usuários do Facebook. Ver, sobre o Brexit, a matéria "Cambridge Analytica teria tido papel crucial no Brexit, diz ex-diretor de pesquisa” (RFI, 2018). Sobre a eleição de Trump, ver: "Empresa que ajudou Trump roubou dados de 50 milhões de usuários do Facebook" (FOLHA DE SÃO PAULO, 2018). No Brasil, em setembro de 2018, o Facebook informou que aproximadamente 30 milhões de contas privadas haviam sido invadidas por hackers (REUTERS, 2018).
} 
cientistas políticos para isso foi a volatilidade do eleitor contemporâneo, que interage e se informa pelas redes mais rapidamente 2 . 0 diretor do Instituto Datafolha, Mauro Paulino, escreveu à época no Twitter, informado por matéria da Folha de S. Paulo, que a impulsão de mensagens nas redes sociais teria influenciado as eleições (CARTA CAPITAL, 2018). Paulino referia-se à notícia do jornal que levantava a suspeita de que a campanha do então candidato Jair Bolsonaro teria se utilizado de empresas para impulsionar conteúdo digital às vésperas da votação ${ }^{3}$.

Como resposta a essa denúncia da imprensa, passou a circular nas redes um vídeo caseiro, exemplo dos textos que pretendemos compreender neste artigo em que 14 pessoas passavam em fila diante da câmera dizendo "Eu sou o robô de Bolsonaro". A fila é iniciada por um cadeirante e, a seguir, homens e mulheres predominantemente brancos e aparentemente de classe média fazem gestos maquinais. Nesse vídeo de 48 segundos, aparecem elementos que remetem ao imaginário da direita, tais como a camiseta com a foto de Sérgio Moro e a inscrição "República de Curitiba" que um dos homens veste, e a reivindicação por voto impresso expressa na blusa de outro homem e na fala de uma mulher. Esse vídeo expõe algumas das práticas que envolvem, em geral, essas formas culturais (memes, gifs, áudios, vídeos, entre outras). Há, no vídeo, a apropriação de uma denúncia em circulação na grande mídia com a pretensão de dar uma resposta a ela, no modo artesanal e cômico de uma performance doméstica de YouTube. Isso lhe confere espontaneidade e, em certo grau, autenticidade. A baixa resolução do vídeo permite que ele seja propagado e assistido em celulares. Sua forma simples é também seu conteúdo: a afirmação de que não há robôs, mas sim uma militância voluntária e ativa.

Como demonstram os estudos de Camila Rocha $(2017,2018)$, a chamada "nova direita brasileira"4, de ideologia libertariana, teve na internet, especificamente no Orkut, seu lugar de organização já no final do primeiro governo Lula, em 2006. Desde então, desenvolveramse, com apoio de empresários, think tanks de formação e divulgação do pensamento neoliberal, e, segundo Rocha (2018, p. 48), um dos fatores que contribuíram para o êxito desse movimento foi "a habilidade no uso (e a própria lógica) das mídias sociais". Ela conclui

\footnotetext{
2 Sobre projeções e resultados das eleições brasileiras, ver a matéria "Por que as pesquisas eleitorais erraram tanto? Entenda a diferença" (DAMASCENO, 2018)

3 Em janeiro de 2019, o WhatsApp passou a restringir no Brasil e outros países reenvio de mensagens para o número de cinco chats, com indivíduos ou grupos. A medida, adotada inicialmente na Índia, em 2018, foi estendida em 2019 a todos os países como uma forma de a empresa tentar contribuir no combate de boatos e informações errôneas.

4 Segundo Fernandes e Messenberg (2018), várias expressões, entre elas "retomada do neoliberalismo", "onda conservadora" e "fascismo à brasileira", são usadas para designar a emergência de setores extremados à direita na política e na sociedade brasileiras. Como assinalam os articulistas, esses termos, pertinentes ou não, são colocados em circulação pela imprensa e a academia e, podemos acrescentar, fazem parte da conversação na vida prática dos cidadãos.
} 
que "as redes sociais e fóruns da internet tiveram papel central no ressurgimento do movimento liberal no Brasil e na sua popularização" (ROCHA, 2017, s. p.). Embora esse não seja o foco de seu estudo, Rocha (2017) levanta alguns aspectos importantes acerca dessas estratégias, como a busca da "nova direita" por uma "linguagem mais popular e descontraída", que ultrapassasse os limites da classe média e dialogasse com setores da classe trabalhadora. Nesse sentido, notamos a forte presença de formas expressivas naturalizadas junto aos usuários de mídias sociais, ou seja, não apenas seus conteúdos, mas também os formatos garantem a adesão imediata de um público cada vez mais alfabetizado na linguagem audiovisual da internet, fundada em elementos humorísticos voltados ao entretenimento.

De fato, nossa hipótese é a de que as formas de entretenimento vinculadas a informação muitas vezes deslocada da mídia dominante são o substrato dos textos midiáticos que circulam nas redes sociais e que, a seu modo, fomentaram grande parte do debate acerca das eleições brasileiras de 2018. Esses textos, ainda que possam dialogar com notícias da imprensa, acabaram por prevalecer sobre as formas jornalísticas tradicionais na informação de grande parte do eleitorado. São textos que demonstram o imperativo do entretenimento ou, como quer Dyer (2002), o esvaecimento dele como categoria cultural e seu enredamento na vida imediata.

Embora essas formas tenham relação com articulações mais antigas entre informação e entretenimento, como os fenômenos da tabloidização e do infotainment, elas possuem características e lógicas próprias que perpassam uma diversidade de textos, tais como memes, gifs, áudios e performances audiovisuais. Em comum, essas formas, geralmente medeiam - também no sentido da apropriação abusiva - informações circulantes nas mídias tradicionais, possuem força de sociabilidade e perfazem comunicação rápida e abrangente, atravessando diversas classes sociais. Elas muitas vezes trazem notícia falsa, mas nem sempre, ainda que a descontextualização mais radical e o caráter ligeiro das mensagens carreguem um tipo de desvirtuamento ao debate e à argumentação mais adensada, ideal nesses contextos.

Isso posto, este artigo divide-se em duas seções principais. Na primeira, discutimos o conceito de entretenimento e alguns modos históricos de sua articulação com a informação para pensarmos a emergência dessas novas formas culturais no debate político. 0 pressuposto é de que, com as redes, o entretenimento tornou-se base cotidiana de comunicação. Não mais restrito à indústria cultural, ele estrutura as formas de argumentação. Na segunda seção, analisaremos os principais aspectos, alguns já elencados 
acima, dessas formas que circularam no período das eleições de 2018, com reflexão sobre como essa hibridação tornou-se estratégia de engajamento.

\section{Entretenimento e hibridações prévias}

O relato do jornalista Severino Motta (2018) acerca de um curso de formação do Movimento Brasil Livre (MBL), ocorrido em novembro de 2018, em casa de show da capital paulista, indica alguns aspectos do esvaziamento da argumentação política. Na reportagem, Motta (2018) constata que "diferentemente de congressos da política tradicional, no [encontro do] MBL não havia nada de sisudo. Cada palestra era pontuada por piadas, os coordenadores do movimento ao tempo todo faziam brincadeiras entre si e trolavam uns aos outros". Na comparação feita pelo jornalista, "era mais ou menos como estar passando o dia num meme" (MOTTA, 2018, s. p.). Motta (2018) expõe dois aspectos da comunicação do MBL: (1) a ênfase no entretenimento, com elogios à performance de um youtuber e referências a Guy Debord - não para criticar a sociedade do espetáculo, mas para afirmá-la como condição para operar no campo político; (2) o método da provocação, em que é preciso "chocar" e "irritar" as esquerdas, pois, de acordo com uma das palestras, "a ridicularização é a arma mais poderosa do homem".

A noção de entretenimento é de difícil definição, ainda que a ênfase nos sentidos e na emoção, e certo grau de ruptura com a vida prática e de instauração de um mundo duplicado têm sido, pelo menos até então, características compartilhadas por suas formas gerais. A palavra deriva do latim inter (entre) e tenere (ter), que, segundo Neal Gabler (1998), designa a condição em que estamos cativos e imersos em um artefato cultural e em nós mesmos.

Por definição, o estado de entretenimento designa um tipo de atenção, de confisco provisório da mente por meio de um interesse continuamente sustentado. Isso significa que podemos estar entretidos com uma variedade de objetos, como uma peça de Shakespeare, uma palestra ou uma série televisiva. Por esse viés, "o entretenimento não é tanto uma categoria de objetos, mas uma atitude em relação a eles" (DYER, 2002, p. 6, tradução nossa) ${ }^{5}$. Isso coloca-nos, da perspectiva da recepção, o caráter idiossincrático do fenômeno o que é entretenimento para um pode não ser para outro, e a condição de se estar entretido pode não durar todo o espetáculo.

${ }^{5}$ No original: "entertainment is not so much a category of things as an attitude towards things" (DYER, 2002, p. 6). 
Uma acepção mais circunscrita de entretenimento começa a se formar a partir do século XIX, em que se consolida um tipo específico de lazer de exploração comercial, programado em determinado espaço e tempo. Dyer (2002) propõe compreender esse entretenimento, que foi apropriado e desenvolvido pelas indústrias culturais, como categoria derivada de formas breves e fragmentadas correntes na diversão da classe trabalhadora em bares e clubes. Elas são marcadas por, entre outras características, conotações sexuais e sentimentalismo exacerbado:

Essa forma tem sido, claro, alimentada pelas tradições persistentes do divertimento burguês - a opereta, a comédia musical, música de salão. Mas isso só tem levado a refinar ou embelezar (e algumas vezes enfraquecer) a forma, não a dominá-la. (DYER, 2002, p. 7, tradução nossa) ${ }^{6}$.

Como categoria cultural, o entretenimento, segundo Dyer (2002), pode ser compreendido como um artefato ou performance (música pop, cinema, quadrinhos, programas televisivos, jogos de computador, romances pulp etc.) feito para um público alargado e com fins mercadológicos. $\mathrm{O}$ entretenimento fundamenta-se numa dinâmica de "separação e fuga" (DYER, 2002, p. 175, tradução nossa)7, isto é, promove a suspensão da realidade imediata e gera uma outra realidade duplicada. Assim, como a ficção, experimenta-se, neste mesmo mundo em que vivemos, um outro mundo, regido por regras próprias e entre parênteses.

A forma do entretenimento é orientada para a diversão e para oferecer às audiências uma sensibilidade utópica por meio de um código afetivo e da inserção na realidade ficcional, em que é possível alcançar de forma plena qualidades que nos são negadas na vida imediata. Essas qualidades são, segundo Dyer (2002), da ordem da energia, abundância, intensidade emocional, transparência e senso de comunidade. 0 autor explica que diversos produtos e performances podem objetivar o prazer, e que também podemos sentir prazer em face de obras bastante variadas, mas "a ideia de entretenimento se distingue na ênfase na primazia de tal prazer, colocado à frente ou mesmo em oposição a objetivos e funções práticas, sagradas, instrutivas e políticas" (DYER, 2002, p. 1, tradução nossa) ${ }^{8}$.

\footnotetext{
${ }^{6}$ No original: "This form has, of course, been fed by the continuing traditions of bourgeois amusement - operetta, musical comedy, parlour songs - but this has only tended to refine or embellish (and sometimes emasculate) the form, not to dominate it" (DYER, 2002, p. 7).

7 No original: "separation and escape" (DYER, 2002, p. 175).

8 No original: "the ideia of entertainment is distinctive in its emphasis on the primacy of such pleasure, ahead or even instead of pratical, sacred, instructional or political aims and fuctions" (DYER, 2002, p. 1).
} 
Assim como Richard Dyer, Luhmann (2005) afirma que o entretenimento não está voltado ao ensinamento; nisso se difere do jornalismo e, também, das formas da política tradicional. Isso não quer dizer que o entretenimento não possa trazer informação ou alguma forma de instrução, mas sua ênfase é no prazer utópico e no divertimento, que se sobrepõe a qualquer outro objetivo. Evidentemente, ainda uma vez, isso deve ser considerado da perspectiva de uma intencionalidade do produtor e das estratégias de linguagem constituintes do artefato, uma vez que sabemos que os usos e os deslocamentos desses textos são tão imprevisíveis como frequentes no âmbito da recepção.

Todavia, as experiências na cultura midiática do século XX demonstraram que o entretenimento é uma categoria cultural mais porosa do que a delimitação teórica pressupõe. Cruzamentos entre entretenimento e jornalismo, por exemplo, podem ser apontados pelo menos desde a imprensa tabloide. De início, o termo (combinação de tablet, pílula, e de alcaloide), que surgiu na Inglaterra na passagem do século XIX para o XX, denominava apenas um formato condensado e adaptado de jornal para o novo público procedente da classe trabalhadora. No entanto, a expressão acabou por se referir a um perfil de jornalismo, que se utiliza de aspectos do entretenimento na base de sua comunicação. No debate culturalista, argumenta-se, a favor da imprensa tabloide, que ela é uma forma popular inclusiva, orientada para um público leitor que, de outro modo, teria menos interesse e acesso a notícias. Além disso, o fato de esse jornalismo rivalizar com a racionalidade comunicativa do campo é, por vezes, como em Fiske (1989), interpretado e valorizado como resistência à ideologia dominante e desafio à ordenação discursiva.

O neologismo tabloidização [tablodization], que surge em países de língua inglesa, na década de 1990, descreve o fenômeno em que a estética e os valores da imprensa tabloide se expandem não somente sobre uma lógica midiática mais geral como também sobre a vida política e cultural. Para Graeme Turner, tabloidização é termo impreciso mesmo na cultura midiática, uma vez que

incorpora programas de estilo de vida, colunas de conselho em jornais, talk shows vespertinos, vídeos produzidos por espectadores, jornalismo de câmera escondida, revistas de fofoca e muitos mais em uma miscelânea de sintomas de um mal-estar cultural. (TURNER, 1999, p. 68, tradução nossa)9.

\footnotetext{
9 No original: "it incorporates lifestyle programming, advice columns in newspapers, afternoon talk shows, viewer video formats, hidden camera journalism, gossip magazines, and much more, into a miscellany of symptoms for a cultural malaise" (TURNER, 1999, p. 68).
} 
O caráter difuso do fenômeno fez com que Biressi e Nunn (2008) preferissem a expressão "cultura tabloide", referente tanto a formatos já históricos como a novas formas híbridas e ainda instáveis que assimilaram o discurso e as práticas desse jornalismo.

Mais corrente em nosso meio cultural, a palavra infotenimento (DEJAVITE, 2006) também nomeia formas híbridas em que se articulam entretenimento e informação. 0 termo “designa, principalmente na televisão, tanto a mistura dos dois domínios no mesmo programa como a tendência a veicular, nos programas, informações atraentes a qualquer preço" (NEVEU, 2006, p. 19). No entanto, o debate acadêmico acerca do infotenimento, a exemplo do que ocorre com a "cultura tabloide" e com formas midiáticas populares em geral, é também polarizado. Na televisão brasileira das últimas décadas, assistimos a uma variação de formatos híbridos, de programas como A liga e CQC (ambos na Rede Bandeirantes) ao atual Greg News (HBO Brasil), passando pela cobertura esportiva e por uma nova geração de talk shows, com apresentadores conservadores politicamente, formados no stand up comedy e atuantes nas redes sociais digitais ${ }^{10}$.

Para Dyer (2002), o modo como o âmbito das notícias e dos documentários faz uso dos recursos do entretenimento e passa a abrir cada vez mais espaço em suas narrativas para tematizar a diversão e o prazer indica, na contemporaneidade, o esvaecimento do entretenimento como categoria cultural. Ele explica, porém, que não se trata do declínio do entretenimento, uma vez que nossa época é acentuadamente hedonista. "O que pode estar em eclipse, contudo, é a provisão de entretenimento por meio de artefatos e performances baseadas na dinâmica da separação e da fuga" (DYER, 2002, p. 175, tradução nossa) ${ }^{11}$. Se até 1920, a prática dominante do entretenimento era oferecida por profissionais e implicava o deslocamento do lar e do trabalho para espaços e tempos outros, como os do cinema, da sala de concerto e do teatro, nossa época tornou o entretenimento onipresente. Inicialmente, isso se deu por meio de aparelhos domésticos, como o gramofone e o rádio, e, mais recentemente, podemos acrescentar, pelas tecnologias móveis, o streaming e as redes sociais, que permeiam não somente o espaço e o tempo do lar, mas também o trabalho flexível e desregulamentado de lógica neoliberal.

Além de mudanças espaciotemporais, o esvaecimento do entretenimento como categoria provoca alterações culturais mais generalizadas, como as já citadas no jornalismo. Dyer (2002) menciona, ainda, contaminações no campo político. Campanhas, conferências e

\footnotetext{
10 Ver sobre isso o livro de Julia Lery (2018), Não é só uma piada - cinismo, ironia e entretenimento nos talk shows "The noite" e "Agora é tarde".

11 No original: "What may be in eclipse, though, is the provision of entertainment in artfacts and performances based on a dynamic of separation and escape" (DYER, 2002, p. 175).
} 
outras atuações políticas tornaram-se segmento do espetáculo, e "mesmo a política alternativa é frequentemente baseada no teatro de rua e na performance de protesto" (DYER, 2002, p. 177, tradução nossa) ${ }^{12}$. Esses fenômenos fusionais brevemente recuperados aqui e que não pretendemos esgotar demonstram que o entretenimento tem transbordado para outros âmbitos na cultura contemporânea.

As formas culturais contemporâneas de embate político a que aludimos na introdução deste artigo emergiram nas redes digitais a partir desse substrato complexo, constituído em um longo processo de combinações entre informação (falsa ou verdadeira) e entretenimento. A expressão "forma cultural" deve ser entendida a partir da concepção que Raymond Williams (2003) dá a ela, como uma forma articulada a uma tecnologia, no caso específico, a da internet, e que materializa um conjunto de demandas e transformações sociais. Ainda segundo Williams (2003), formas culturais desenvolvem-se a partir de formas anteriores, e, possivelmente, esses textos midiáticos contemporâneos herdaram elementos de processos preliminares, marcados, entre outros, pela suspensão da realidade e instauração de uma realidade ficcional própria, por um código afetivo, por uma comunicação sintética e simplificadora, por um riso sarcástico. No entanto, trata-se também de combinações novas, que se desenvolveram e ainda se desenvolvem em um dado contexto ideológico e a partir dos usos de um novo meio e de seus modos de interação, que precisamos investigar.

\section{Das fake news à desinformação}

Em agosto de 2018, Ivan Paganotti, Leonardo Sakamoto e Rodrigo Ratier, professores universitários e jornalistas, desenvolveram o curso online "Vaza Falsiane", sobre fake news (os modos de identificá-las e combatê-las) para um público mais amplo. Hospedado no site vazafalsiane.com e com páginas no Facebook, Instagram e canal no YouTube, o curso utiliza uma linguagem semelhante àquela das redes, contando com memes, testes, depoimentos, áudios, vídeos, gifs e outros materiais populares na internet. Para Rodrigo Ratier, em entrevista ao podcast As árvores somos nozes (2018), do Greenpeace Brasil, um ponto a ser ressaltado é que as fake news, embora mais visíveis durante processos eleitorais e políticos, estão presentes em várias áreas, como saúde, meio ambiente, celebridades, entre outras. Além disso, deve-se distinguir o fenômeno mais particular das fake news de outro maior,

${ }^{12}$ No original: "even alternative politics is often based on street theatre and the performance of protest" (DYER, 2002, p. 177). 
passível de checagem, legislação e retratação, genericamente denominado como desinformação (envolvendo boatos, difamações, calúnias, teorias da conspiração ou doutrinação, descontextualizações, interpretações equivocadas, opiniões sem fundamentação, fraudes, entre outros).

De acordo com os jornalistas, as fake news possuem intenção deliberada de manipular e enganar o público. São distribuídas exclusivamente pelas redes digitais e imitam formatos jornalísticos para parecerem verossímeis (PAGANOTTI; LIBÓRIO, 2018). No entanto, como veremos, as agências de checagem não fazem essa última distinção, pois se ocupam de uma diversidade de materiais que não necessariamente replicam os formatos tradicionais da mídia noticiosa. No caso desta pesquisa, os textos analisados tangenciam o fenômeno das fake news, mas delas se diferenciam - pelo menos no sentido mais restrito proposto acima, de imitação da forma jornalística -, pois trata-se de material que se vale das formas do entretenimento para alcançar um efeito informativo, mas que na maior parte dos casos apenas reforça convicções ou crenças já compartilhadas por determinados indivíduos ou grupos.

Ao assumirmos que uma nova articulação entre informação e entretenimento tem se acentuado em fenômenos comunicativos recentes, especialmente de caráter político, faz-se necessário indagar como as pessoas se apropriam, utilizam e circulam tais conteúdos, ou seja, como recebem e propagam esses materiais difundidos nas redes digitais e mídias sociais. Em pesquisa-ação sobre o consumo cultural de estudantes do ensino médio residentes nas periferias de São Paulo - SP, Juliana Doretto, ao investigar como os jovens veem o jornalismo atual, destaca que as fontes de informação tradicionais geram, entre eles, "distanciamento" e "desconfiança". Novas rotinas noticiosas, sobretudo aquelas presentes nas redes digitais e utilizadas em mídias sociais, contrapõem-se às mídias corporativas, como relatado pela autora: "Por iniciativa própria, os jovens recorrem a posts em redes sociais, vídeos no YouTube e consultas a aplicativos, para acessar o que eles identificam como 'notícias' importantes para o dia a dia" (DORETTO, 2019, p. 66).

Se em diversas situações os jovens, bem como outros grupos sociais cada vez mais segmentados pelas ferramentas e aplicativos de largo uso na internet, têm se informado por meios mais voltados ao entretenimento, podemos afirmar que isso se deu, de modo mais geral, durante o debate eleitoral brasileiro em 2018. Em um cenário polarizado, a desinformação ocupou espaço central na disputa. Um dado inédito, no Brasil, foi a utilização do aplicativo de troca de mensagens WhatsApp de modo mais ostensivo do que aquele antes realizado pela rede social Facebook, proprietária do primeiro desde 2014. Por meio de um 
marketing agressivo, uso de dados, formação de grupos e identificação de perfis de usuários, esses conteúdos atingiram graus elevados de eficácia, sendo direcionados a nichos específicos de público tomando como base suas preferências de consumo, visões de mundo e modos de interação nas redes ${ }^{13}$.

Reportagens publicadas em diferentes sites da mídia tradicional ou por agências de checagem de notícias, ambas mobilizadas para a contenção e denúncia de conteúdos mentirosos ou notícias falsas, mapearam essa produção. Entre 16 de agosto e 7 de outubro, a Agência Lupa, uma das principais checadoras de notícias falsas, analisou 50 imagens que circularam em 347 grupos públicos do WhatsApp, das quais apenas quatro se mostraram verídicas, apontando para o grau de "intoxicação da vida política brasileira", contaminada por milhares de mensagens falaciosas e determinantes para as escolhas dos eleitores (TARDÁGUILA; BENEVENUTO; ORTELLADO, 2018). No Facebook, rede social de acompanhamento mais direto, durante o primeiro turno das eleições, as dez notícias falsas mais populares checadas pela Agência Lupa tiveram 865 mil compartilhamentos, dividindose em: vídeos postados em busca de popularidade; fotos adulteradas; teorias da conspiração; questões morais e de cunho sexual; e depoimentos de pessoas famosas ${ }^{14}$.

Em amostragem de 50 imagens analisadas pela Agência Lupa a pedido de um grupo de pesquisadores do projeto "Eleições sem fake", sediado na Universidade Federal de Minas Gerais (UFMG), pode-se atestar o aumento de mensagens agressivas e disseminadoras de preconceitos de inúmeros tipos, contrárias ao grupo de eleitores pertencente ao campo progressista e seu candidato, e direcionadas para o favorecimento do candidato de direita. Curiosamente, como destacado pela Lupa, oito dessas imagens possuem caráter claramente ideológico, ainda que se coloquem como negação de ideologias, que no caso se aplicam apenas ao ideário do campo progressista. Dentre elas, selecionamos duas que consideramos representativas para a temática tratada ${ }^{15}$.

\footnotetext{
${ }^{13}$ Sobre uso do WhatsApp nas eleições brasileiras, ver matéria do HuffPost (2018), no Brasil.

14 Para reportagem completa sobre o primeiro turno, ver a matéria "Dez notícias falsas com 865 mil compartilhamentos: o lixo digital do 1‥ Turno" (TARDÁGUILA; MARÉS, 2019).

15 Em termos de resultados, "oito eram falsas; 16 eram reais, mas usadas fora de contexto ou com dados distorcidos; quatro eram insustentáveis, ou seja, não se baseiam em nenhum banco de dados público confiável. Isso significa que $56 \%$ das imagens mais compartilhadas nesses grupos eram enganosas. Apenas $8 \%$ das 50 imagens mais populares nesse universo foram consideradas verdadeiras" (MARÉS; BECKER; RESENDE, 2018).
} 
Figuras 1 - Exemplos de imagens falsas

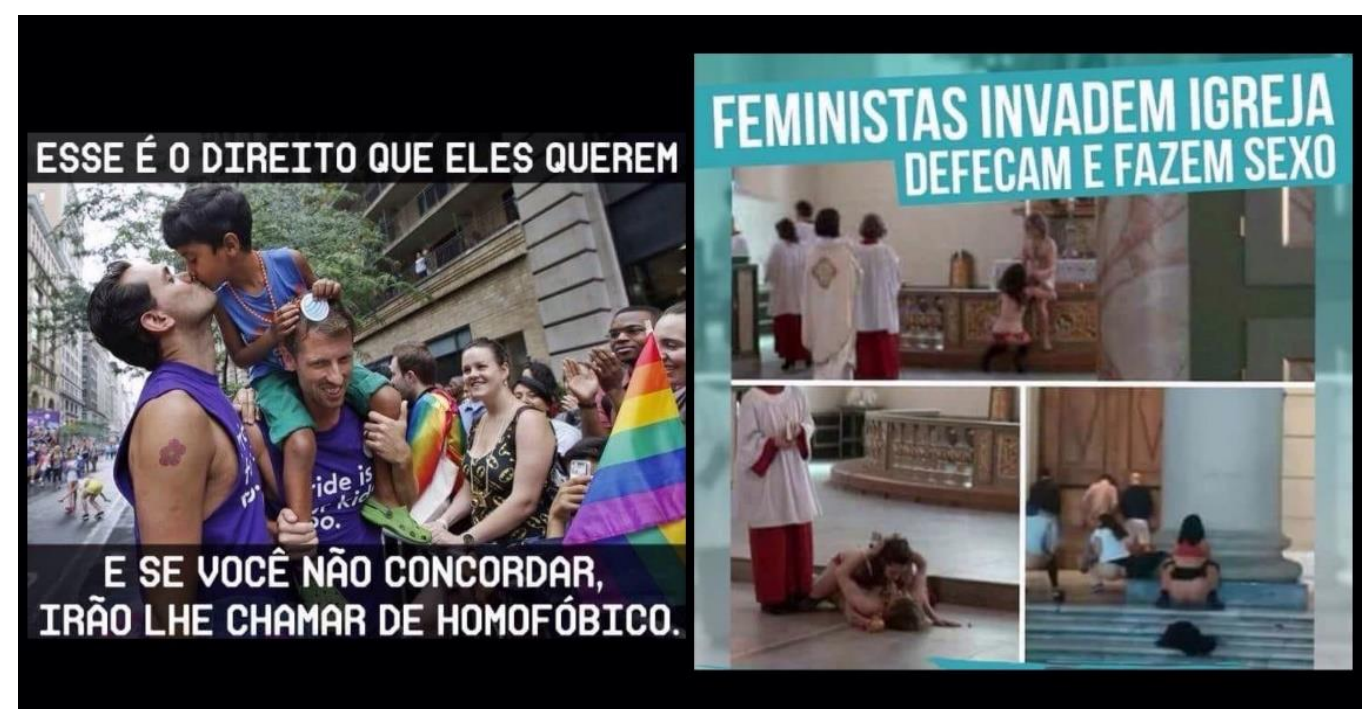

Fonte: Agência Lupa (2018).

A imagem da esquerda, com texto bastante claro em relação a seus objetivos, vinha acompanhada da informação de que se tratava de pessoas relacionadas à Rede Globo ("globolixo") que, supostamente, não votariam em Jair Bolsonaro. De acordo com a Lupa, o registro data de junho de 2015 e foi feito durante a Heritage Pride March, em Nova Iorque, uma das maiores paradas gays do mundo. A imagem da direita, por sua vez, circulou em diversas redes sociais e refere-se a uma montagem feita a partir de registros fotográficos de eventos distintos - nenhum deles relacionados a movimentos feministas no Brasil. Segundo a Lupa, o primeiro registro, na metade superior da montagem, mostra um casal fazendo sexo em Oslo, capital da Noruega, em 2011. Conforme apurou a agência Lupa, a partir de informações do jornal San Francisco Chronicle (DICUM, 2012), dos Estados Unidos, eles fazem parte de um grupo que acredita que a prática sexual em espaços públicos aumenta a conscientização sobre a natureza.

Na parte inferior, as imagens são de um protesto realizado na catedral de Buenos Aires, Argentina, em 2015, segundo reportagem do jornal Clarín (2016), contra a vitória de Maurício Macri nas eleições presidenciais daquele ano. Em 2016, a foto foi usada como sendo de uma catedral na Espanha. Essa montagem, com texto com verbos no presente e em sequência "invadem", "defecam" e "fazem sexo", imitam a manchete de um jornal sensacionalista e suas gradações. As fotos tiradas de longe, com faces pouco nítidas, são como aquelas de registro de flagra de celebridades. A comunicação rápida, ao estilo tabloide, é sobre a profanação do sagrado, por meio do sexo e pelo ato de defecar, vistos como manifestações rebaixadas do corpo em um discurso moral. 
No mapeamento de três outros grupos públicos no WhatsApp, o padrão se repete: mentiras disfarçadas de notícias, vídeos fraudulentos, falso apoio de celebridades, desmoralização das pesquisas e do sistema eleitoral. Com volume de centenas de mensagens por dia, cada um dos grupos realizou, sistematicamente, um trabalho de descrédito da mídia de referência e apregoou o poder do usuário em buscar as fontes de informação com as quais se identifica e nas quais confia. Muitos desses conteúdos são responsivos, isto é, produzem textos que tratam de desmentir e desfazer outras notícias, ainda que a maioria deles não utilize formatos próximos ao jornalismo ou a formas convencionais de produção de conteúdos para as mídias sociais (BENITES, 2018). É o que podemos constatar também nas imagens abaixo, extensamente replicadas ao longo do processo eleitoral ${ }^{16}$.

Figuras 2 - Três exemplos de imagens falsas

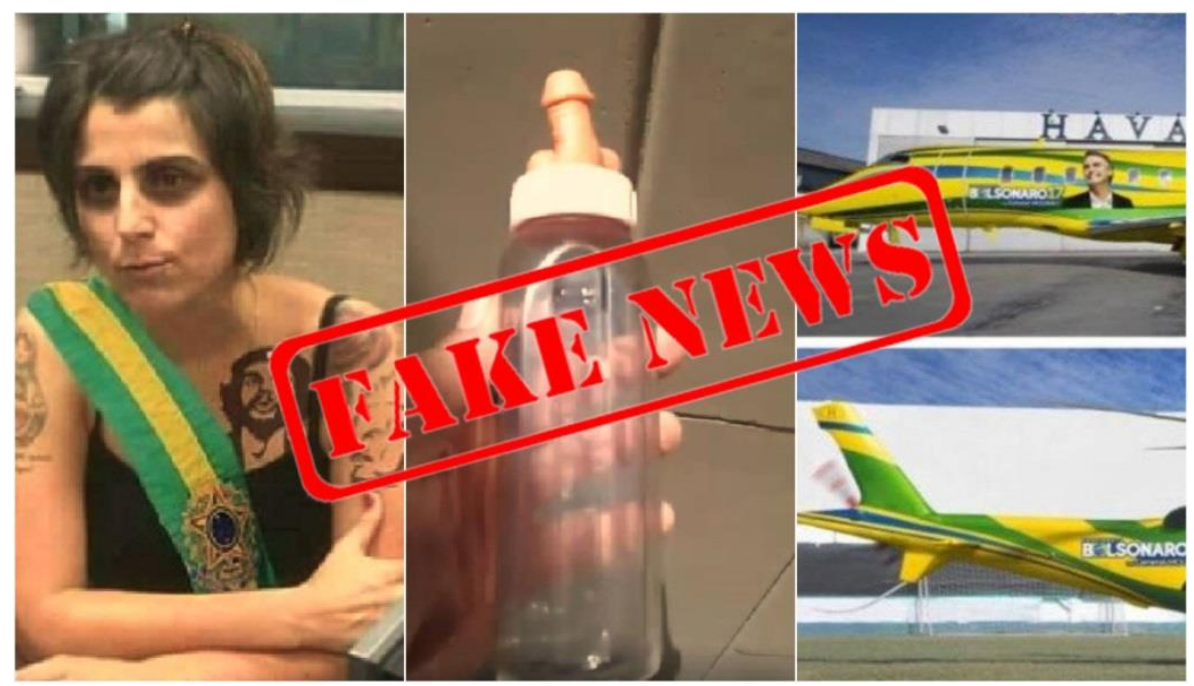

Fonte: El País (2018b).

Na primeira delas, Manuela D’Ávila, candidata a vice-presidente na coligação PTPCdoB, é retratada em montagem mostrando tatuagens de líderes "comunistas" (Che Guevara e Lênin), inseridas digitalmente, bem como a faixa presidencial utilizada para amedrontar os eleitores sobre o caráter da futura "presidente". Na segunda imagem, a "mamadeira erótica", uma das mais compartilhadas nas redes, é atribuída ao candidato Fernando Haddad, que teria distribuído esse objeto em creches de São Paulo quando foi prefeito da cidade, supostamente para estimular a homossexualidade infantil. Nesse caso, valeu mais a narrativa do que sua plausibilidade. Finalmente, vemos aviões e helicópteros

16 Para informações sobre a utilização de imagens deturpadas e textos fraudulentos ver matéria "Os 'whatsapps' de uma campanha envenenada", publicada no El País (2018b). 
pintados com as cores do Brasil e a imagem de Jair Bolsonaro, fato celebrado por grupos a favor do candidato e atribuído ao dono da rede de lojas Havan, que declarou apoio a Bolsonaro, mas não imprimiu essas figuras nas aeronaves.

\section{Considerações finais}

As complexas articulações entre entretenimento e informação no embate político brasileiro nestas primeiras décadas do século XXI se tornaram ainda mais intensas desde as eleições de 2018 e com a ascensão ao poder de grupos ideologicamente conservadores e reacionários. Como vimos, a desinformação e a disseminação de informações falsas por meio de discursos que oscilam entre o humor e a agressão se tornaram formas expressivas corriqueiras nas diferentes redes sociais, ancoradas, como buscamos demonstrar, em um substrato cultural constituído historicamente por hibridações. Em suas diversas manifestações, tais formas acabaram por se mesclar ou substituir aquelas próprias do jornalismo de referência, funcionando como fragmentos aparentemente informativos, mas que operam, sobretudo, no reforço de crenças já estabelecidas. Os exemplos destacados confirmam a prevalência da lógica do entretenimento no debate político, não à maneira convencional de pensá-lo como manifestação de uma cultura popular, mas como um dispositivo no qual a vinculação com o mundo histórico se torna irrelevante ou mesmo inexistente.

É o que pode ser comprovado quando observarmos a grande quantidade de textos produzidos e a variedade de formas em circulação nas redes digitais durante as eleições de 2018, como relatado em reportagem da BBC News Brasil, que acompanhou 272 grupos políticos públicos no WhatsApp ${ }^{17}$. A matéria elencou diferentes modos de "desinformação", que podem ser confirmados nas análises, relacionando as teorias apresentadas aos dados empíricos referentes: (1) imagens descontextualizadas, áudios com teorias conspiratórias, fotos manipuladas, pesquisas falsas; (2) ataques à mídia tradicional, montagens com capas falsas, checagem falaciosa de notícias verdadeiras; (3) imagens e vídeos disseminando ódio a minorias sociais, especialmente mulheres, negros e gays; (4) ataques a artistas, agentes e produtores culturais, ativistas e defensores dos direitos humanos; (5) áudios e vídeos de

\footnotetext{
17 O uso do WhatsApp tem se mostrado intenso no Brasil. Por se tratar de uma rede fechada e criptografada, é de difícil monitoramento, facilitando a troca de mensagens em grupos, modo usual de comunicação nessa ferramenta. Para além do envio, o grau de interação nos grupos, privados ou públicos, carrega uma dinâmica ágil e interativa, podendo reunir até 256 pessoas. Dados do Instituto Datafolha apontam que "120 milhões de pessoas utilizam o aplicativo de mensagens diariamente e $90 \%$ o fazem mais de 30 vezes por dia. $66 \%$ dos eleitores brasileiros consomem e compartilham notícias e vídeos sobre política por meio da rede social mais popular do país" (OLIVEIRA; ROSSI, 2018).
} 
gente comum sem identificação ou fonte, com relatos testemunhais ou lives que atestam apoio ou rejeição a candidatos, mas que podem ser textos produzidos profissionalmente com atores ou locutores, como vimos nas imagens acima.

Em grande parte, esses materiais, cuja produção e disseminação apoiam-se em estruturas profissionais e sofisticadas, vão de textos lúdicos a debochados, de sarcásticos a violentos. Eles apelam para a intensidade emotiva de grupos segmentados, explorando, por exemplo, sentimentos de medo e ódio, sustentado por visões preconceituosas e moralistas do mundo. A cultura espraiada do entretenimento não apenas fornece as formas para esses textos, mas também a possibilidade de suspensão de uma realidade imediata para que se possa vivenciar um mundo à parte, onde operam produtivamente narrativas que não estão sob o jugo do factual. 0 caráter difuso daquilo que não pode ser mais caracterizado como informação em sua contraposição ao entretenimento torna-se mais evidenciado pelas diversas maneiras com que os jovens, mas não apenas eles, apropriam-se dessas formas como elementos noticiosos que possam auxiliá-los a compreender e interpretar a realidade.

Há, portanto, formas disseminadas de fake news que são veiculadas como se fossem notícias de jornal; muitas outras, contudo, fazem uso de estratégias de uma cultura tabloide, ancorada no entretenimento, para veicular desinformação sem necessariamente querer se passar por notícias do jornalismo dominante. Apelam, assim, para outras narrativas e, mais recentemente, contrapõem-se diretamente tanto ao discurso jornalístico quanto ao discurso científico relacionado à produção de conhecimento em espaços acadêmicos ou universitários. Para engajar audiências, os formatos aqui analisados partem do entretenimento e adquirem caráter informativo nos usos e aplicações dados a eles por leitores, ouvintes ou espectadores. 0 que permanece é a questão de como essas formas são tomadas e redistribuídas à guisa de notícia e como e por que elas passam, na recepção, a conviver com ou mesmo a prevalecer sobre aquelas do jornalismo dito de referência.

0 fato de Jair Bolsonaro ser eleito presidente sem ter participado de debates no segundo turno - fato inédito desde a redemocratização do país, sempre que houve essa etapa do pleito - revela que esse fórum estabelecido, com mais possibilidade de confrontação de argumentos, não foi considerado imprescindível por parte significativa do eleitorado. A apresentação mais formalizada de um plano de governo ou a proposição de soluções para os diversos problemas do país em temas estabelecidos na política, tais como saúde, educação, transporte, segurança, trabalho, entre outros, também não foram levadas em conta pelos eleitores, que se sentiram e foram informados por meio desses formatos sintéticos de comunicação. 
No contexto brasileiro, notadamente, podemos afirmar que a tensão entre o campo progressista e o campo conservador tem fundamentado os embates políticos ocorridos desde 2013, e orientou as eleições de 2018. Naquele ano de pleito eleitoral, como demonstramos, vimos o compartilhamento intensivo de textos mentirosos ou distorcidos, muitas vezes de cunho preconceituoso e estereotipado, com alto grau de autoritarismo e intimidação, de violência verbal e visual18. Essas formas híbridas mesclam-se comumente a elementos próprios do humor, como paródias, sátiras ou pastiches, cobertos por diferentes graus de ironia, deboche ou sarcasmo e produzindo, assim, diferentes efeitos de sentido junto ao público.

É assim que, como buscamos sublinhar, o substrato cultural contemporâneo formado a partir das articulações prévias entre entretenimento e informação - contribui para o estabelecimento de formas de sociabilidade mais ou menos primárias (no ambiente doméstico, no trabalho, na igreja) que passam a atuar também sobre a troca e a interpretação desses textos. Os processos sociais envolvidos nessa dinâmica sinalizam caminhos para a compreensão de como os indivíduos leem, interpretam e usam esses materiais, e para novas articulações dos âmbitos do entretenimento e da informação em contextos políticos atuais.

\section{Referências}

AS ÁRVORES somos nozes. \#04 - Eleições 2018: como lidar com boatos, Fake News e desinformação? [Locução de]: Paulina Chamorro. Entrevistado:Rodrigo Ratier. [S. l.]: Greenpeace Brasil, 02 nov. 2018. Podcast.

BENITES, A. A máquina de 'fake news' nos grupos a favor de Bolsonaro no WhatsApp. El País, Brasília, 28 set. 2018. Disponível em: https://brasil.elpais.com/brasil/2018/09/26/politica/1537997311_859341.html. Acesso em: 4 fev. 2019.

BIRESSI, A; NUNN, H. The tabloid culture reader. New York: Mc Graw Hill, 2008.

BRUM, E. O homem mediano assume o poder. El País, São Paulo, 04 jan. de 2019. Disponível em: https://brasil.elpais.com/brasil/2019/01/02/opinion/1546450311_448043.html Acesso em: 01 maio 2021.

\footnotetext{
${ }^{18}$ Ainda que o uso esteja presente em diferentes tendências, em relação às eleições no Brasil dados confirmam que a maioria dos conteúdos compartilhados visava desconstruir a elegibilidade de um dos candidatos, Fernando Haddad, identificado com o campo progressista, ou se voltavam contra o Partido dos Trabalhadores (PT). Além disso, segundo pesquisa entre usuários de Facebook e Twitter, 98,2\% dos eleitores do presidente eleito foram expostos a esses produtos, e 89,7\% deles acreditaram em conteúdos enganosos (PASQUINI, 2018).
} 
CARTA CAPITAL. Pesquisas evidenciaram impulsão de mensagens, diz diretor do Datafolha. Carta Capital, São Paulo, 18 out. de 2018. Disponível em:

https://www.cartacapital.com.br/politica/pesquisas-evidenciaram-impulsao-demensagens-diz-diretor-do-datafolha/. Acesso em: 17 jan. 2019

CLARÍN. Papelón: criticó a militantes de Podemos por orinar una catedral, pero la foto era de Argentina. Clarín, Buenos Aires, 8 dez. 2016. Disponível em:

https://www.clarin.com/mundo/diputado-militantes-podemos-catedralargentina_0_BJygay0uPme.html. Acesso em: 19 jun. 2021.

DAMASCENO, R. Por que as pesquisas eleitorais erraram tanto? Entenda a diferença. Correio Braziliense, Brasília, 8 out. 2018. Disponível em: https://www.correiobraziliense.com.br/app/noticia/politica/2018/10/08/interna_politica, 711021 /por-que-as-pesquisas-eleitorais-erraram-tanto-entenda-a-diferenca.shtml. Acesso em 25 jan. 2019.

DEJAVITE, F. A. Infotenimento - informação + entretenimento no jornalismo. São Paulo: Paulinas, 2006.

DICUM, G. Eco-porn: great sex for a good cause. San Francisco Chronicle. São Francisco, 9 fev. 2012. Disponível em: https://www.sfgate.com/homeandgarden/article/GREEN-Ecoporn-Great-Sex-For-A-Good-Cause-3175838.php. Acesso em: 19 jun. 2021.

DORETTO, J. A mídia manipula quem tem cabeça fechada: adolescentes periféricos e a crítica ao jornalismo. Estudos em Jornalismo e Mídia. Florianópolis, v. 16, n. 1, p. 66-7, 2019.

DYER, R. Only entertainment. 2. ed. London, New York: Routledge, 2002.

EL PAÍS. Notícias falsas ameaçam processos eleitorais na América Latina. El País, São Paulo, 14 mar. 2018a. Disponível em:

https://brasil.elpais.com/brasil/2018/03/14/internacional/1521060611_975112.html. Acesso em 0 fev. 2019.

EL PAÍS. Os 'whatsapps' de uma campanha envenenada. El País, São Paulo, 28 out. 2018b. Disponível em:

https://brasil.elpais.com/brasil/2018/03/14/internacional/1521060611_975112.html. Acesso em 1 maio 2021.

FERNANDES, D. C.; MESSENBERG, D. Um espectro ronda o Brasil (à direita). Plural, São Paulo, v. 25, n.1, p. 1-12, 2018.

FERRÉZ. Periferia e conservadorismo. In: GALLEGO, E. S. (org.). 0 ódio como política. São Paulo: Boitempo, 2019. p. 61-64.

FISKE, J. Understanding popular culture. Boston: Unwin Hyman, 1989.

FOLHA DE SÃO PAULO. Empresa que ajudou Trump roubou dados de 50 milhões de usuários do Facebook. Folha de S. Paulo, São Paulo, 17 mar. 2018. Disponível em: https://www1.folha.uol.com.br/mundo/2018/03/empresa-que-ajudou-trump-rouboudados-de-50-milhoes-de-usuarios-do-facebook.shtml Acesso em: 31 jan. 2019. 
GABLER, N. Life: the movie - how entertainment conquered reality. New York: Random House, 1998.

GORDON, J. Is everything wrestling? The New York Times Magazine, New York, 27 maio 2016. Disponível em: https://www.nytimes.com/2016/05/27/magazine/is-everythingwrestling.html. Acesso em 31 jan. 2019.

HUFFPOST BRASIL. Bolsonaro, o fenômeno de Whatsapp que desbancou 3 décadas de campanha de tv. Huffpost Brasil. São Paulo, 04 nov. 2018.

LERY, J. Não é só uma piada: cinismo, ironia e entretenimento nos talk shows "The noite" e "Agora é tarde". Belo Horizonte: Editora PUC Minas, 2018.

LUHMANN, N. A realidade dos meios de comunicação. São Paulo: Paulus, 2005.

MARÉS, C; BECKER, C; RESENDE, L. Imagens falsas mais compartilhadas no WhatsApp não citam presidenciáveis, mas buscam ratificar ideologias. Agência Lupa, Rio de Janeiro, 18 out. 2018. Disponível em: https://piaui.folha.uol.com.br/lupa/2018/10/18/imagens-falsaswhatsapp-presidenciaveis-lupa-ufmg-usp/. Acesso em: 04 fev. 2019.

MOTTA, S. Isto é o que vimos e ouvimos no curso de formação política do MBL.

BuzzFeed.News, [s.l], 23 nov. 2018. Disponível em:

https://www.buzzfeed.com/br/severinomotta/isto-e-o-que-vimos-e-ouvimos-no-curso-deformacao-politica. Acesso em: 31 jan. 2019.

NEVEU, E. Sociologia do jornalismo. São Paulo: Loyola, 2006.

OLIVEIRA, J; ROSSI, M. WhatsApp, um fator de distorção que espalha mentiras e atordoa até o TSE. El País, São Paulo, 07 out. 2018. Disponível em:

https://brasil.elpais.com/brasil/2018/10/07/politica/1538877922_089599.html. Acesso em: 6 fev. 2019.

PAGANOTTI, I; LIBÓRIO, B. Visões do jornalismo \#8. [Entrevista cedida a] Juliana Doretto. São Paulo: YouTube, 20 mar. 2018. Duração 25 min.

PASQUINI, P. 90\% dos eleitores de Bolsonaro acreditaram em fake news, diz estudo. Folha de S. Paulo, São Paulo, 02 nov. 2018. Disponível em: https://www1.folha.uol.com.br/poder/2018/11/90-dos-eleitores-de-bolsonaroacreditaram-em-fake-news-diz-estudo.shtml. Acesso em: 06 fev. 2019.

PINHEIRO-MACHADO, R. Os ricos, os pobres e os precariados: os três tipos de eleitores de Bolsonaro. The Intercept Brasil, Rio de Janeiro, 16 out. 2018. Disponível em: https://theintercept.com/2018/10/16/tipos-eleitores-bolsonaro. Acesso em: 04 fev. 2019.

REUTERS. Facebook diz que hackers roubaram dados de 29 milhões de usuários. G1, [s.l], 12 out. 2018. Disponível em:

https://g1.globo.com/economia/tecnologia/noticia/2018/10/12/facebook-diz-quehackers-roubaram-dados-de-29-milhoes-de-usuarios.ghtml. Acesso em: 06 fev. 2019. 
RIBEIRO, M. M.; ORTELLADO, P. O que são e como lidar com as notícias falsas. Sur, Rev. int. direitos human., [s. l]. v. 15, n. 27, p. 71-83, 2018.

RFI. Cambridge Analytica teria tido papel crucial no Brexit, diz ex-diretor de pesquisa. G1, [s.l.], 27 mar. 2018. Disponível em: https://g1.globo.com/mundo/noticia/cambridgeanalytica-teria-tido-papel-crucial-no-brexit-diz-ex-diretor-de-pesquisa.ghtml. Acesso em: 31 jan. 2019.

ROCHA, C. $\mathrm{O}$ boom das novas direitas: financiamento ou militância? In: SOLANO GALLEGO, E. 0 ódio como política: a reinvenção das direitas no Brasil. São Paulo: Boitempo, 2018. p. 4752 .

ROCHA, C. Passando o bastão: a nova geração de liberais brasileiros. Nuevo mundo, mundos nuevos. [En ligne] Colloque, Pensar las derechas en América latina, siglo XX, Paris, 2 octobre, 2017. DOI: https://doi.org/10.4000/nuevomundo.71327.

TARDÁGUILA, C; MARÉS, C. Dez notícias falsas com 865 mil compartilhamentos: o lixo digital do $1^{\circ}$ turno. Agência Lupa, Rio de Janeiro, 7 out. 2018. Disponível em: https://piaui.folha.uol.com.br/lupa/2018/10/07/artigo-epoca-noticias-falsas-1-turno/. Acesso em: 06 fev. 2019.

TARDÁGUILA, C.; BENEVENUTO, F.; ORTELLADO, P. Fake News is poisoning Brazilian politics. WhatsApp can stop it. The New York Times, New York, 17 out. 2018. Disponível em: https://www.nytimes.com/2018/10/17/opinion/brazil-election-fake-newswhatsapp.html. Acesso em: 3 fev. 2019.

TURNER, G. Tabloidization, journalism and the possibility of critique. International Journal of Cultural Studies, [s. l.], v. 2, n. 1, p. 59-76, 1999.

WILLIAMS, R. Televisão: Tecnologia e Forma Cultural. São Paulo: Boitempo, 2016.

\title{
The new forms of the false: entertainment, misinformation and politics in the digital network
}

\begin{abstract}
By analyzing some cultural forms (memes, gifs, audios, videos, among others) that circulated in the digital networks during the Brazilian 2018 elections, this essay investigates how entertainment and information were articulated in the political discussion, and false information was disseminated through discourses that ranged from playfulness to violence. The hypothesis is that these forms, emerging from a cultural substratum historically constituted by process of hybridization, have ended up juxtaposing or even overlapping, in everyday life, those of mainstream journalism. The communication of these forms, by the means of professional structures, operated with
\end{abstract}


narratives of emotional intensity for segmented groups. As in the logic of entertainment, a world apart was created, in which the connections with immediate reality became irrelevant.

\section{Keywords}

Communication. Politics. Entertainment. False Information. Journalism.

\section{Autoria para correspondência}

Marcio Serelle

marcio.serelle@gmail.com

Rosana de Lima Soares

rolima@usp.br

\section{Como citar}

SERELLE, Marcio; SOARES, Rosana de Lima. As novas formas do falso: entretenimento, desinformação e política nas redes digitais. Intexto, Porto Alegre, n. 52, e-94842, jan./dez. 2021.

DOI: http://dx.doi.org/10.19132/1807-8583202152.94842

Recebido em 25/07/2019

Aceito em 01/02/2021

(c) $(1)(9)$ 